(5) The foraging instinct may be due to chronic hunger. (6) Regulation takes place in the sphere of instinct as well as in the sphere of morphology. (7) The social instincts cannot be used to support any of the mechanical theories of development.

Bethe's contention that ants and bees are merely reflex machines, to which we must not even ascribe sensations, is no longer tenable; for the researches of the past year have demonstrated that the behavior of the higher invertebrates is not a series of tropisms, but the result of a psychic complex ranging from simple sensations up through memory. Although we have no evidence of reasoning in its highest phases, yet here and there we catch glimpses of what Hobhouse calls a practical judgment.

HaiNes NorMial, School,

C. H. Turner. AUGUSTA, GA.

\title{
RECENT LITERATURE ON MAMMALIAN BEHAVIOR.
}

\section{The Establishment of Habits.}

In an important contribution to the behavior of raccoons, Cole ${ }^{1}$ describes in detail their methods of learning to release the fastenings of various problem boxes. The boxes were similar in nature and complexity to those used by Thorndike, Kinnaman and others in their tests upon monkeys.

The time records of the four raccoons for the learning of these fastenings show greater variability than those of cats and monkeys. In the rapidity of forming associations, the raccoon stands almost midway between the monkey and the cat. In regard to the complexity of association, Cole states that the raccoon deserves a place closer to the monkey than to the cat. Davis ${ }^{2}$ in a similar study on a much larger number of raccoons ( 12 ) reaches a conclusion similar to the above. On page 475 of his article he plots a curve (6), the data for which was obtained from Kinnaman's study of the monkey. The curve represents a series of thirty trials each on nine simple locking devices. Davis compares this with a similar curve obtained from the raccoons on the same (or closely similar) devices. The general character of the learning curves for both animals is the same. According to Davis, the monkeys are a little less clever at the start than the raccoons. Also the curve for the monkeys is slightly more irregular than

${ }^{1}$ Cole, L. W., ' Concerning the Intelligence of Raccoons,' Jr. Comp. Neurol. and Psy., Vol. XVII., No. 3, May, I907.

${ }^{2}$ Davis, H. B., 'The Raccoon; A Study in Animal Intelligence,' $A m$. $J r$. Psychology, Vol. XVIII., No. 4, 1907. 
that of the raccoon; this would point to the conclusion that the monkey is slightly more open to distraction than the raccoon. Cole and Davis are thus seen to be somewhat at issue on the question of variability.

Davis brings out the added points that the young animals are more reckless in their expenditure of energy than the old, consequently they solve the various problems at first more rapidly than the adults; and that all through their work the young animals show a greater variability than the adults.

An interesting contested point has been raised between Davis and Cole: Cole found that when he changed the position of fastenings the trained animals never began work at the parts of the box where the fastening had previously been placed, but went at once to the new position of the fastening. Davis' results are opposite: He found that several of his animals did persistently work at the place where a mechanism customarily had been located before finally discovering it in its new position. The question is raised here because the reviewer has found, as has every other investigator up to the present time, that the 'position' error is the most fundamental and deeply rooted error which occurs in mammalian reactions. If Cole is right, it would appear that the sensory control of the raccoon is effected more largely by means of distance sense data than that of most mammals which have so far been observed in the laboratory. Davis suggests that Cole's results in this particular are exceptional.

Yerkes $^{3}$ in his study of the dancing mouse presents results on the learning of simple mazes by those animals. He makes the astonishing statement that the dancer did not form a perfect habit in labyrinth $A$ (only fairly complex). He states that the fault is not in the nature of the maze but lies in the fact that no motive for following the correct path could be made sufficiently strong (the dancer does not withstand the effect of hunger according to Yerkes). The common mice tested in this same maze learned rapidly to escape from it. In mazes of other types, by using punishment (electric shocks) as a stimulus to escape, he succeeded in establishing uniform maze habits in the dancer.

\section{Tests on Vision.}

Yerkes ${ }^{3}$ presents a satisfactory account of the reactions of the dancer to chromatic and achromatic light stimulation.

He finds that the dancer can discriminate white from black perfectly and that two grays lying as near together as Nendel's Nos. Io and 20

${ }^{3}$ Yerkes, Robert M., The Dancing Mouse, The Macmillan Co., New York, 1907. 
can just be discriminated. In regard to Weber's law, Yerkes states that a difference of one tenth is sufficient to enable the dancer to distinguish two lights in the case of three standard values 5,20 and 80 hefners."

Cole tested the ability of raccoons to discriminate black from white, black from hues, and between complementary colors. In his first test the animals in order to obtain their food had to select a box covered with black, white or colored paper. Since the employing of colored papers in tests on color vision is embarrassed by our inability to control the factor of brightness, Cole's results may be classed possibly as discriminations between grays. His black-white test is the only one where the conditions are unambiguous. In the first experiments the animals had to select the black box from the white: $\mathrm{He}$ found that they learn to discriminate black from white in from $70-90$ trials. His later tests were made with an apparatus devised by himself and called a 'card displayer.' Here the different grays and colored cards were shown in succession and not simultaneously as has usually been done. He was enabled by this method to get the animals to distinguish between black-white, black-red, black-yellow, black-blue, black-green, blue-yellow and red-green. The complementary color (?) discriminations took longer than either the black-white discrimination or the black-color discrimination. He makes the important statement that the range of effective visual discrimination is extremely short, never more than $\mathrm{I} S$ inches. Davis' results on visual discrimination in raccoons confirm those of Cole, except that Davis, since he presented six possibilities of choice instead of two, obtained a relatively smaller percentage of right choices.

Yerkes, ${ }^{3}$ working with approximately monochromatic light filters on the dancer, is the first investigator to arrange an adequate test for color discrimination. His own conclusions are stated as follows : "Although the dancer does not possess a color sense like ours, it probably discriminates the colors of the red end of the spectrum from those of other regions by difference in the stimulating value of light of different wave-lengths, that such specific stimulating value is radically different in nature from the value of different wave-lengths for the human eye, and that the red of the spectrum has a very low stimulating value for the dancer." This conclusion, if correct, concerning the difference in the

'In my review of Yerkes' book in the Jour. of Philosophy, Psychol. and Scientific Methods, I misstated Yerkes, by saying that a satisfactory demonstration of Weber's law could not be obtained in the case of the brightness vision of the dancer. 
stimulating effect of waves of different length, is a fundamental one in our further consideration of tests on color vision. If it be still further substantiated, it clearly shows the uselessness of testing the color vision of animals with light reflected from colored papers.

- O. Pfungst ${ }^{5}$ shows that nearly all of the wonderful answers returned by the horse, kluger Hans, were reactions to visual cues, such cues being afforded by the involuntary movements made by his questioners. If Hans could see his questioner, he could answer any question which could be answered by tapping a certain number of times witl the foot. The way in which Hans reacted to the involuntary move ments of his questioner may be seen in the following extract from Pfungst's book: After Herr von Osten (the owner of Hans) had stated the problem, he tended alzways, involuntarily, to bend the head and trunk slightly forward, whereupon Hans would extend his right foot and begin to tap without putting his foot back after each successive tap. When the desired number of taps was reached, Herr von Osten would, involuntarily, give a slight upward jerk of the head. At this second signal, the horse would retract the foot to its normal position. By this study of Pfungst we are shown the delicacy of the visual cues to which the horse can react, the width of his range of vision and the delicate functioning power of his peripheral retina.

Cole ${ }^{1}$ has shown that raccoons learn easily to discriminate between square cards and round cards, and between two square cards, $6.5 \times 6.5$ inches and $4.25 \times 4.25$ inches respectively. The animals, owing to their previous practice in brightness discrimination, learned to make the correct responses very rapidly.

Yerkes ${ }^{3}$ tested the dancer's ability to discriminate between a round food box $(5 \mathrm{~cm}$. in diameter and $1.5 \mathrm{~cm}$. in depth) and a rectangular box $(8.5 \mathrm{~cm}$. in length and $2.5 \mathrm{~cm}$. in depth). He found that the dancer, under the conditions of the test (direct hunger-food stimulus, without punishment), could not make the discrimination. Yerkes urges, in commenting upon this test, that the negative results obtained do not preclude the possibility that the animals might have formed the discrimination provided a sufficiently strong motive were at hand. However, in a test of discrimination between an illuminated circle and a form of cross, in which he used the punishment method, he failed to get the desired reaction.

\section{Auditory Discrimination.}

Cole $^{2}$ showed that his raccoons learned to discriminate between the highest tone, $A_{1}$, of a French harp, and its lowest tone, $A^{\prime \prime}$.

'Pfungst, O., Kluger Hans, das Pferd des Herm von Osten, Berlin, 1907. 


\section{Tests on Retention.}

Cole ${ }^{1}$ found that the retention of simple fastenings was perfect after intervals of three or four days, and in some cases even after two weeks. His tests with a box possessing very complicated fastenings ( 7 separate acts), which proved to be about the most difficult box the raccoons could learn, are interesting: Raccoons Nos. 3, 2 and I were tried on this box after an interval of 147 days. Only No. 3 showed a perfect mastery after such an interval. The other two worked almost, but not all, of the fastenings. Cole considers this interval to be about the maximum for the retention of complicated fastenings. Davis likewise shows that simple fastenings are retained by the raccoon for periods of one year. In a crucial test he found that the association of a complicated fastening persisted, with a certain loss, over a period of 286 days (including hibernation). An expression of the efficacy of retention in that instance was determined as follows: On relearning after this period, 24 trials were necessary to attain the perfect standard which had in the original learning process required 107 , and the times of these 24 trials were much shorter than the first 24 trials of the primary learning process.

Yerkes ${ }^{3}$ shows that the dancer's retention of a black-white or white-black discrimination may persist over an interval of from two to eight weeks. Retention of such a habit, however, is seldom perfect after four weeks. The same author shows that a habit (black-white discrimination) which after an interval of eight weeks has been lost by the dancer can be reacquired in a much shorter time than was necessary for the original acquiring of it. $\mathrm{He}$ gives indices of modifiability as follows:

$\begin{array}{lcc} & \text { Learning. } & \text { Relearning. } \\ \text { Females, } & \text { IO4 } & 42.5 \\ \text { Males, } & 72 & 54\end{array}$

Yerkes mentions the fact that there are great individual differences in the retention of discrimination habits. In this connection he shows that the acquisition of one labyrinth habit aids the animal in learning a different labyrinth.

\section{Learning from Being Put Through an Act.}

A large part of Cole's ${ }^{1}$ paper is devoted to proving that, contrary to Thorndike's results on cats, raccoons will learn to reënter a box of their own accord into which they have been passively dropped and then allowed to go out and get the food; and further that they can learn fairly complicated sets of acts by being put through them. Cole 
generalizes on his first set of experiments as follows: "Since four raccoons exhibited this reaction, it is safe to conclude that any raccoon which has been lifted into a box and allowed to come out and be fed will sooner or later go in of his own accord, and further that he will go in before the rooth trial and probably before the $75^{\text {th }}$ trial as my four animals did. The behavior of these animals forces one to believe that it dawns on the animal that he can hurry the matter of getting food by rushing back into the box and coming out again. . . . I should say, rather, that it had an image of the interior of the box as the starting point of the food getting process and an idea of going back to recommence the process."

In order to test whether the animals could learn to undo fastenings by this artificial method of teaching the following experiments were tried: Two raccoons were allowed to learn certain problem boxes by trial and error, and two (the stupider two) were put through the acts. The average time of the first success in manipulating each of the II boxes was, for the animals which were put through the act, 4r.6 sec.; for those not put through, 90.2 , or more than twice the above average. In these tests, the animals did not always perform the act in the way in which it had been taught. They were put through the acts with one forepaw: they performed the acts with that paw, with the other forepaw and with both forepaws. "And exactly the same is true of those who learned the fastenings by trial and crror" (italics mine).

The animal can be made to learn the act in the way in which he was put through it. "If the act which he is put through is the one which will remain the easiest and most convenient for him throughout the tests, irrespective of his position in the box, he will never vary from it. If not, he will employ your act when his position makes it convenient and he is looking at the latch you began with." (Surely he does not mean this statement to be taken literally!) Cole further says that the raccoon can learn and act from being put through it, even though it has failed to learn it by its own efforts.

In commenting upon Cole's results, it may be said that in his discussion he has left out one or two very important factors: First and foremost, putting the animal through a large number of times would naturally lead it to attack the moving parts of the apparatus when trying to solve the problem alone. In other words, putting the animal through need not tend to produce the rise of an idea; it might have the effect merely of limiting the area of attack upon the problem-box. The learning process as he describes it even when the animal is put 
through was slow enough for us still to be able to call the type of learning involved merely ' abbreviated trial and error.' The fact that the animals put through did not use the same system of movements employed in putting them through the act, but one similar to those utilized by the animals which had learned by trial and error, leads one to think that what was gained by the animal was the ability to attack the problem-box at the point where the mechanism is located. Then, too, the situation is not new to those animals which have been 'put through' the problem, and the diffuse, time-consuming, motor overflows usually present on all first trials are not present in their case.

\section{Learning by Imitation.}

Cole ${ }^{1}$ maintains all through his paper that he has found abundant evidence of imagery and of the rise of ideas in his raccoons, yet he was unable to find the function of imitation present. "I have no evidence that the raccoon imitates his fellows. Long attention to the experimenter's movements apparently arouses in the animal an impulse to attempt the act itself, but this impulse may be entirely spontaneous." Davis ${ }^{2}$ notes only one or two cases of possible ' instinctive' imitation, but claims that he observed no cases of imitation of a higher order of one animal by another. Yerkes ${ }^{3}$ after varied and complete tests on the dancer finds no evidence of imitation: "Although abundant opportunity for imitation in connection with the opening of the doors in the discrimination box was given to twenty-five, I obtained no evidence of ability to learn by imitation." The same author's experiments upon the imitation of a climbing feat are just as conclusive in showing the absence of any tendency to imitate on the part of the dancer.

Watson's ${ }^{6}$ experiments on rhesus and cebus monkeys show (in the particular animals studied at least) that the function of imitation in its higher forms is lacking. Some evidence for a circular type of reaction was offered.

Berry, ${ }^{7}$ on the other hand, in a paper on the imitative tendency of the white rat finds evidence both for an instinctive and a possible voluntary type of imitation. His method of studying imitation was to allow one animal to establish an association (problem box of the manipulation type) by the trial and error plan and then to allow a second untrained animal to be present with the trained animal as the latter per-

${ }^{6}$ Watson, John B., Imitation in Monkeys. See this number of the BULIETIN.

${ }^{7}$ Berry, Charles Scott, 'The Imitative Tendency of White Rats, Jour. Comp. Neurology and Psychology, Vol. XVI., No. 5, September, I9o6. 
formed the necessary act. The untrained animal was then tested alone for a certain number of minutes. If he failed in the allotted time, the trained animal again showed the trick to the untrained animal. Berry lays emphasis upon the watching of one rat by another and assumes that the imitation (?) occurred through a visual process. He made no effort to test the visual acuity of the white rat, but apparently assumes that it dwells in a highly organized visual perceptual world ${ }^{8}$ (which would be a conditio sine qua non in any act of imitation which was visually initiated). The work of Small, of Watson, and of Carr and Watson has established (if any fact in comparative psychology can be said to be established) that the rat uses kinæsthetic data for control in all situations like that of the maze; Dr. Florence Richardson (whose results are at present unpublished) has just shown that vision is practically a negligible factor in the reactions of the rat to problem boxes of the type used by Berry and that the sensory control in these situations as in those offered by the maze is kinæsthetic. In the reviewer's mind, this mass of data makes Berry's results entirely untenable so far as showing the presence of imitation in the white rat. What factors may have been present to give Berry such results are at present not known to the reviewer. Several possible ones were certainly present: Individual variation; more thorough habituation to box on part of imitatee; determination of specific stimulus (i.e., position of mechanism, going out of door, etc.); but possibly more important still is the subtle way in which the presence of one animal may influence another by raising the general physiological tonus of a second animal. As an example of this I cite the following: Four female rats were especially lazy and stupid in learning the maze; each would enter, work for a few moments and then lie down. If now another animal was put in the maze, the former would immediately show signs of activity and begin again upon the problem. This increase in the general tonus of the organism as a whole was in all probability brought about partly through contact stimulation, partly through general olfactory stimulation, and through specific olfactory stimulation by the odor of the sexual organs.

The same author's ${ }^{9}$ experiments upon imitation in Manx cats are almost equally open to criticism - it is still an assumption (here possibly a safe one) even in the case of Manx cats to proceed upon

${ }^{8}$ Cf. Mead, G. H., 'Concerning Animal Perception,' Psychological, REVIEW, October, I907.

9 Berry, Charles Scott, 'An Experimental Study of Imitation in Cats,' Jour. Comp. Neurology and Psychology, Vol. XVIII., No. I, 1908. 
the supposition that vision of a kind suitable to the perception of the acts of another animal is present. His experiments were conducted upon an adult Manx female and her three kittens. The type of problems resemble in some cases those used by Hobhouse, such as getting food (with paw) from a bottle, rolling a ball into a hole, climbing down from a table, learning to catch and kill mice, etc. In all of these experiments, the author finds evidence of the presence of imitation. On the whole, the work on the cat demands slightly more scientific consideration than that on the rat, but the reviewer is far from accepting the conclusions of Berry-especially the conclusion he reaches in regard to the catching and killing of mice. To draw the conclusion that the young cat catches, kills and eats mice by imitation from such uncontrolled, experimental evidence as Berry offers - evidence obtained from only one litter of cats and from a very short part of the life history of the animals at that - comes fairly close to making inferences without evidence.

Vil. Experimental Evidence for the Presence of Mental. IMAGERY.

Cole ${ }^{1}$ cites in detail an interesting reaction on the part of his raccoons which he believes cannot be explained, even taking into account the law of parsimony, without maintaining the presence of visual imagery. The reaction referred to appeared in tests made upon the 'card displayer' mentioned above. Two cards, say a red and a green, were presented in succession; the animal had to react to the green card by climbing up on a high box for food, but had to remain inactive when the red card was displayed. After the animals had been tested in this way for some time, they began clawing the 'no food' card (red) down, and sometimes the 'food' card (green) up. This variation in response was fostered until some of the animals became fairly proficient in the act. Cole reasons concerning it as follows: "When the animal thus reacts perfectly to red and green, and in addition busies himself in clawing the red card down and the green card up, surely his discrimination of the two is perfect. Now we are forced to ask, Why should he put the red card down if it did not fail to correspond with some image he had in mind, and why, when he put the green up, should he leave it up and go up on the high box for food if the green did not correspond with some image he had in mind?"

The responses thus obtained are exceedingly interesting, but it certainly strains our credulity to suppose that these animals can have 
separate images for a series of different shades of gray. (Cole in a later place in the paper admits that the animals so far as visual discrimination is concerned were probably reacting to the differences in the white values of the cards.) Davis ${ }^{2}$ attempts with some success to offer a different explanation for the above reaction. He suggests that "It was an accidental result of the raccoons' inveterate impulse to attack and manipulate anything that can be moved. The animals had already associated the colored cards with the getting of food; had earlier still been accustomed to get food by attacking some sort of fastening; from this it is a short step - hardly a step at all — to attack card-holders. After having succeeded a few times in thus starting the train which leads to feeding, the activity would become stereotyped like the opening of boxes or any other." The reviewer fails to see why this explanation of Davis' is not an adequate one; it is certainly more nearly in line with what we know elsewhere of mammalian activity.

The incidental observations running all through Cole's work, lending support to his contention regarding the presence of imagery, are certainly not of a convincing character.

\section{Vili. The Kinfesthetic Character of Certain Sensory}

\section{Control Processes.}

Carr and Watson, ${ }^{10}$ in experiments with a new form of maze, have found that the white rat trained to run the maze always from the entrance, attains orientation, when put down at unfamiliar starting points in the maze, by making certain exploring movements before getting the cue which leads to the establishment of the automatic character of the remaining part of the series of acts. By detailed experiments which cannot be cited in the review, the authors concluded that, in obtaining orientation, a kincesthetic cue might serve the same purpose for the rat as a distance sense cue for man.

In this same paper the authors advance still further evidence for the general kinæsthetic character of the sensory control of these animals. This evidence came from tests on a maze, the straightaways or alleys of which could be lengthened or shortened at will without disturbing the number of the turns or their relations. The animals which had learned the lengthened form of the maze and were then suddenly introduced to the shortened form, in nearly all cases ran squarely into the ends of the alleys affected by the change. On the average, sixteen trials

${ }^{10}$ Carr and Watson, 'Orientation in the White Rat,' Jour. Comp. Neurology and Psychology, Vol. XVIII., No. I, I908. 
per rat were necessary to restore automatic adjustment to the changed conditions. On the other hand, the animals which had become habituated to the shortened form and were then introduced to it in its lengthened form attempted to round corners at the old distances regardless of the fact that the alley into which they then should have turned was further along in the course.

Yerkes $^{3}$ in testing the dancer in the labyrinth states that, after the maze is learned, probably no sense data is necessary for the guidance of these animals in the performance of such a series of acts: "A habit once formed, the senses have done their part; henceforth it is a motor process, whose initiation is conditioned by the activity of a receptive organ (at times a sense receptor), but whose form is not necessarily dependent upon immediate impressions from eye, nose, vibrissæ, or even from internal receptors. These are statements of my opinions; whether they express the truth, either wholly or in part, only further experimentation can decide." The reviewer does not know clearly what these statements mean. If Yerkes means to say that a series of acts learned in the beginning (consciously or unconsciously) by means of the activity of the distance sense receptors or of internal receptors or by means of both combined, can be later carried out by means of kinæsthetic-motor responses alone (without the accompaniment of consciousness), he would be restating merely the generally accepted teaching on habit. If, on the contrary, he means to imply that there is even in a perfectly established habit a cessation of neural functions of the internal (kinæsthetic) receptors, every case of locomotor ataxia or other sensory disturbance should lead him to change such an opinion.

It is to be regretted that neither Cole ${ }^{1}$ nor Davis ${ }^{2}$ in their respective studies on the raccoon devised tests for isolating the function of kinæsthetic sensations (receptions).

J. B. W.

\section{THE ANIMAL MIND.}

The Animal Mind. A Text Book of Comparative Psychology. Margaret Floy Washburn. New York, Macmillan, 1908. Pp. $x+333$. \$r.6o.

Professor Washburn's book is the second of a series of volumes on animal behavior, of which the first appeared in 1907 entitled The Dancing Mouse by Dr. Robert M. Yerkes, the editor of the series.

In general design and arrangement of matter the book is adapted for the purpose of a text-book of animal psychology. 